ISSN 1112-9867

Available online at $\quad$ http://www.jfas.info

\title{
DEVELOPMENT OF A MULTILAYER STRUCTURE FOR POWER UNIT ACOUSTIC SHIELDING
}

\author{
I. F. Shaehova*, S. M. Vakhitova, I. F. Gumerov \\ Kazan Federal University, Naberezhnye Chelny Institute
}

Published online: 08 August 2017

\begin{abstract}
The article presents the theoretical aspects of noise protection device development for the power unit of trucks, as well as the practical research and experimental development of materials for the production of acoustic capsules. The studies of physical-mechanical, heatconducting, sound-absorbing, vibration-absorbing properties of various polyurethane materials were carried out. The prospect of polymeric composite materials use as the acoustic protection of trucks has been revealed.

One of the main problems of modern ecology is the noise pollution of the environment. More and more people feel the negative impact of noise on general health condition. Transport noise, as the main source, prevails in industrial environment [1]. The mechanisms and the systems of vehicle power units are the main source of both external and internal noise of transport. The requirements for the noise of cars throughout the history of vehicles are tightened constantly. Nowadays, the noise of vehicles is normalized by the national standard of Russian Federation GOST R 41.51 (UNECE Regulation No. 51). According to the document, the maximum value of the total noise level is in the range of 74-80 dBA.

Key words: noise, truck, polyurethane, composite material, sound absorption, thermal conductivity, vibration absorption.
\end{abstract}

Author Correspondence, e-mail: irrra1603@yandex.ru

doi: http://dx.doi.org/10.4314/jfas.v9i2s.76 


\section{INTRODUCTION}

Despite the world experience in the design of vehicle noise reduction tools, there is a need to find new and more effective solutions to reduce vehicle noise. The problem of noise reduction is technically conditioned by the characteristics of power units and the layout solutions of a car as a whole $[2,3,4,5]$.

The reduction of the noise emission of trucks, thereby the significant reduction of the overall levels of internal and external noise will allow the introduction and the improvement of an integrated system of design and technological measures.

Let's analyze the methods of automobile engine noise reduction. The classification of noise protection means and methods is described in GOST 12.1.029. Noise protection means that do not use an additional energy source are considered passive, and the means in which an additional energy source is used are considered to be active. The active means of protection work on the principle of attenuating interference between acoustic fields, which are formed by "primary" noise sources, whose sound field must be reduced, and by "secondary" sources, whose sound field is superimposed on the mutable sound field [6, 7]. It should be noted that active noise protection systems are ineffective for noise process muffling in road transport, unreliable in operation (especially under conditions of high dynamic and temperature loads) and relatively expensive. Therefore, they are not widely used in mass production. In parallel with this, the means of collective and individual protection are distinguished. The consideration of individual means of protection against noise in relation to a car driver and passengers is not advisable.

The means of collective protection in relation to a source of noise excitation are subdivided: reducing noise in the source of its occurrence and reducing noise on the way of its propagation from a source to a protected object. The reduction of noise in a source of its occurrence is achieved by the reduction of noise excitation or the sound-emitting ability of a noise source.

A possible method of combat airborne noise is the soundproofing of a power unit by its shielding. This method is also called an acoustic encapsulation of an internal combustion engine body and a gearbox. An acoustic capsule can be made of a dense sound-reflecting metallic or a polymeric shell layer, including the one, covered (lined) on the inside by a sound-absorbing material. The effectiveness of this method depends on the properties of the used sound-absorbing materials and the design (the configuration) of an acoustic capsule body. The problems of noise emission of power unit isolation have been and still are the subject of research by many scientists $[8,9,10,11,12]$. 


\section{MATERIALS AND METHODS}

Acoustic materials are divided into vibration-damping, sound-absorbing, sound-proof and combined ones $[13,14,15]$. A lot of attention is paid to the development of new vibrationand sound-absorbing, vibration- and sound-insulating, combined materials, which is proved by the number of registered patent documents.

The disadvantages of soundproofing method are that the mass of a vehicle and its cost increases, and in the low-frequency region this method is not effective enough. Most materials used for noise suppression are fire hazardous. The indicator of car maintainability is decreased, since after the repair work performance, the properties of the soundproofing structure deteriorate inevitably. Besides, the shielding (encapsulation) of power units of vehicles complicates the process of heat removal from the thermally loaded surfaces of its housing and makes it difficult to ventilate an engine compartment.

\section{RESULTS AND DISCUSSION}

The choice of materials for the manufacture of all structure components is conditioned by a variety of factors. The material of an outer layer should provide a framework, be resistant to external influences during the operation of a car. The materials of an inner layer of noise insulation are the main functional component of noise shields, their choice should be made on the basis of a deep acoustic analysis of power unit characteristics.

All materials for acoustic shielding should have a minimum specific gravity, resistance to water, dirt, ozone aging, the effects of diesel fuel and motor oils, and be non-combustible and well suited to processing.

Fasteners should provide an easy installation and the removal of screens for prompt repair and inspection.

The work on the improvement of acoustic screens of trucks was started with the analysis of the acoustic characteristics of internal combustion engines of trucks [16].

The results of measurements concerning engine noise levels of different models are shown on Figure 1. 


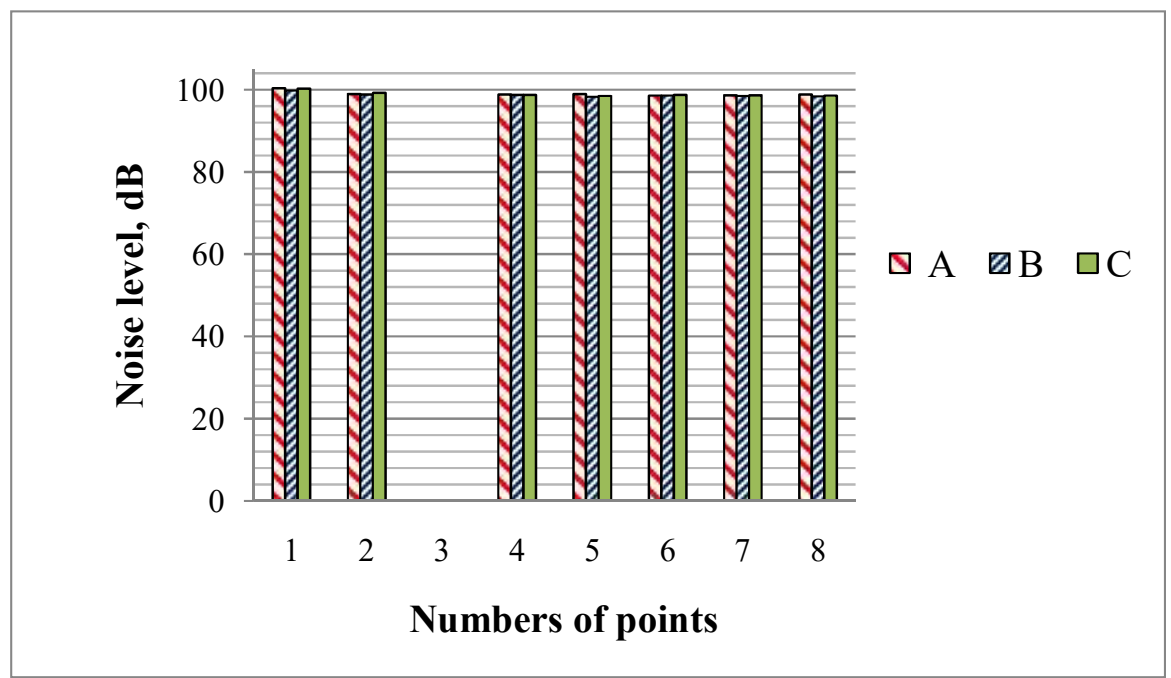

Fig.1. The noise level of engine in control points at $1900 \mathrm{rpm}$.

An average noise level of an engine on a measuring surface was $L m A=99 \mathrm{~dB}$. The maximum engine noise level mod. $\mathrm{C}$ is fixed in t. 1 and made $100.3 \mathrm{~dB}$ at $1900 \mathrm{rpm}$.

The conducted studies showed that the maximum noise level in t. 1 is fixed in the engine of mod. A and made $100.4 \mathrm{~dB}$, which is 0.6 and $0.1 \mathrm{~dB}$ higher than that of mod. B (99.8 dBA) and $\mathrm{B}(100.3 \mathrm{dBA})$ engine, respectively.

The highest values of sound pressure were observed in the octave bands of 1000 and $2000 \mathrm{~Hz}$ and amounted to $1900 \mathrm{rpm}$ among the mod. B - 94.5 and $94.1 \mathrm{~dB}$, mod. A - 95.1 and $95 \mathrm{~dB}$, mod. C - 94 and $95.5 \mathrm{~dB}$.

Conclusions: the highest values of sound pressure in all engine models were observed in the octave bands of 1000 and $2000 \mathrm{~Hz}$ and were in the range of 94 and $95.5 \mathrm{~dB}$.

Next, the well-known sound-absorbing and structural materials of noise-reducing screens of an engine compartment used in the automotive industry were considered: Fiberglass NPmT, MBOR-S-5, MBOR-5F, Al-Aralamino, Izomat, AA 12.5 SMT, AA 25 SMT.

Fiberglass NPMT is a glass-filled composite material consisting of a filler and a binder of a polyester resin of a certain type. The filler performs a reinforcing function and provides the necessary strength. Polyester resin gives the material a monolithic quality, contributes to the effective use of glass fiber strength and the distribution of forces between fibers. In the structures of acoustic screens it serves as a rigid framework layer - the basis for the fastening of lining noise-absorbing material. The coefficient of polyester fiberglass thermal conductivity varies from 0.3 to $0.5 \mathrm{~W} / \mathrm{m} \cdot \mathrm{K}$. It refers to the class of difficult combustible 
materials in accordance with the GOST 12.1.044-89, autoignition temperature is more than $500 \mathrm{C}^{\circ}$, it is resistant to chemically aggressive media and salt solutions.

The materials MBOR-S-5, MBOR-5F is the canvas made from super-thin basalt fiber, sewn by a knitting-broaching method with or without lining material. The material is nonflammable, non-explosive and non-toxic one. The materials based on basalt fibers have low thermal conductivity $(\lambda=0.045 \div 0.09 \mathrm{~W} / \mathrm{m} \cdot \mathrm{K})$, a high sound absorption capacity at medium frequencies and it is chemically stable.

Sound-absorbing materials AL-Aralamino and Izomat are high-density materials quilted with aluminum foil (Izomat has a low-density layer of polyurethane foam) on a self-adhesive basis. It is used for sound and heat insulation of machinery, equipment and exhaust pipes. They have a low coefficient of thermal conductivity (AL-Aralamino $\lambda=0,038 \mathrm{~W} / \mathrm{m} \cdot \mathrm{K}$ Izomat $\lambda=$ $0,041 \mathrm{~W} / \mathrm{m} \cdot \mathrm{K})$, good sound-absorbing characteristics, chemically and heat-resistant.

The materials AA 12.5 SMT, AA 25 SMT is the group of self-adhesive noise-reducing materials based on foamed polyurethane, dubbed with a metallized film. They have a low thermal conductivity $\lambda=0.036 \mathrm{~W} / \mathrm{m} \cdot \mathrm{K}$, average values of sound absorption coefficient, are self-extinguishing in accordance with GOST 25076, are prone to the absorption of working fluids, water and dirt, which worsen technological quality significantly.

During the analysis of these noise-absorbing materials, they found that the materials under study do not correspond to the set of established norms and requirements for noise-proof materials used for trucks (operating temperature range from $-70 \mathrm{C}^{\circ}$ to $+1000 \mathrm{C}^{\circ}$, thermal conductivity coefficient $0.37 \div 0,41$, the coefficient of sound absorption is $0.65 \div 90$ ).

In this regard, it is required to search for and develop new composite materials that can be used as more effective materials for noise-proof screening of trucks.

Fiberglass based on a polyester matrix can be successfully replaced by the fiberglass based on a rigid polyurethane matrix with a lower specific gravity, which makes it possible to reduce the total weight of a power unit acoustic capsule.

They performed the studies of a rigid glass-filled PPU manufactured through innovative technology "Fiber Composite Spraying". The polyurethane system contains a polyol component (SPECFLEX 753), an isocyanate component B (SPECFLEX 138) in the ratio of polyol-isocyanate components of 1.8:1. Glass-roving was used as a filler in the amount of 25 mass parts per 100 mass parts of the matrix component [17].

In order to assess the physical and the mechanical properties of fiberglass based on rigid polyurethane foam, it was tested to determine the breaking stress at bending and Shore D hardness. The results of the measurements are shown in Table 1. 
Table 1. Results of tests of physical and mechanical properties of rigid glass-filled polyurethane foams

\begin{tabular}{|l|c|}
\hline \multicolumn{1}{|c|}{ Index } & Value \\
\hline Breaking stress at bending, MPa & 49,4 \\
\hline Hardness Shore D & $60-69$ \\
\hline
\end{tabular}

The results of sound absorption, thermal conductivity and dynamic modulus of elasticity study of the developed composite materials based on an elastic polyurethane foam matrix with a polyol-isocyanate ratio of 125:100, and fillers-aerosil and aluminum hydroxide are presented in Table 2 .

Table 2. Characteristics of the developed noise-absorbing polymeric composite materials

\begin{tabular}{|c|c|c|c|c|c|c|}
\hline \multirow{2}{*}{ Filler } & \multirow{2}{*}{$\begin{array}{l}\mathrm{E}_{\mathrm{D}} \\
\mathrm{MPa}\end{array}$} & \multirow{2}{*}{$\begin{array}{c}\lambda \\
\mathrm{W} / \mathrm{m} \cdot \mathrm{K}\end{array}$} & \multicolumn{4}{|c|}{$\mathrm{C}_{\mathrm{SA}}$} \\
\hline & & & 800 & 1000 & 1250 & 1600 \\
\hline- & 93 & 0,117 & 0,25 & 0,30 & 0,20 & 0,06 \\
\hline $\begin{array}{l}\text { Aerosil } \\
\vartheta=0,3\end{array}$ & 95 & 0,095 & 0,5 & 0,57 & 0,48 & 0,46 \\
\hline $\begin{array}{l}\text { Aluminum hydroxide } \\
\qquad \vartheta=0,3\end{array}$ & 326 & 0,146 & 0,46 & 0,75 & 0,70 & 0,50 \\
\hline
\end{tabular}

\section{CONCLUSION}

The result of unfilled polyurethane composition study with a different ratio of polyolisocyanate components, showed that the highest coefficient of sound absorption CSA was represented by the matrix modified composition with the component ratio of $125: 100$. The subsequent filling of this composition with aerosil, aluminum hydroxide increased the sound absorption coefficient of dispersed material obtained samples. It should be noted that when it is filled with an aerosol, the dynamic modulus of elasticity and the coefficient of thermal conductivity change insignificantly, while at the filling with aluminum hydroxide, the coefficient of thermal conductivity increases with respect to the matrix sample by $25 \%$ approximately, and the dynamic modulus of elasticity increases in more than three times, which indicates the worsening of vibration damping properties. 
It is the best of the studied filled composite materials on the basis of an elastic foam polyurethane matrix with dispersed filler the volumetric content of which is equal to thirty percent because it showed consistently high values of the sound absorption coefficient and increased thermal conductivity over the entire frequency range from 800 to $1600 \mathrm{~Hz}[18,19$, 20]. The problem of vibration isolation for acoustic capsules is preferable to be solved by the introduction of flexible dampers in the fastening units of screen frameworks to the bearing elements of a vehicle structure [21].

It is also noted that the use of aluminum foil as a working layer increases both the sound absorption coefficient (the increase occurs unevenly over the entire frequency range) and the coefficient of thermal conductivity (by about 5\%). Aluminum foil together with the composite material acts as an additional source of thermal energy and sound wave dissipation. The use of corrugated aluminum foil enhances this effect.

\section{SUMMARY}

The analysis of the performed work shows the possibility of operational performance characteristic improvement concerning the acoustic screening of a truck power unit. The use of a lighter frame material made of rigid glass-filled polyurethane foam, manufactured using the "Fiber Composite Spraying" technology, reduces the total weight of an acoustic capsule. The use of the developed noise-absorbing dispersion-filled composite material based on elastic polyurethane foam and aluminum hydroxide reduces the sound pressure level in the range from 800 to $2000 \mathrm{~Hz}$, increases the heat transfer from the heated elements of an engine. The use of dampers in the mounting area helps to reduce the transmission of vibrations, replacing the brackets of fasteners for quick-release locks and reduces the complexity of assembly and repair operations for acoustic screens.

\section{ACKNOWLEDGEMENTS}

The work is performed according to the Russian Government Program of Competitive Growth of Kazan Federal University.

\section{REFERENCES}

1. Khamkov V.I. Mental conditions as the indicator of human operator activity success under the influence of noise: the thesis of psychological science candidate: 19.00.03. Kazan, 1999. 2. Alfredson R.I. and Davis P.O.A.L., Performance of exhaust silencer components, J. Sound Vib. (1971), 15(2), pp. 175-196. 
3. Razumovsky M.A. Fighting the noise of tractors. Ed. by the Doctor of technical sciences, prof. Chudakov D.A. Minsk: Science and Technology, 1973. - 206 p.

4. Auregan, A. Debray, R. Starobinski, Low frequency sound propagation in a coaxial duct: application to sudden area expansion and to dissipative silencers, Journal of Sound and Vibration, Volume 243, Issue 3, 2001, pp. 461-473.

5. Eversman W., White J.A. Plane Wave and Finite Element Models of Induction Manifolds. 15th International Congress on Acoustics, Trondheim, Nor-way, 26-30 June 1995, vol. 1, pp. 25-28.

6. Vasiliev A.V. Acoustic modeling and comprehensive noise reduction of automotive internal combustion engines: Monograph.

7. Drozdova L.F., Kudaev A.V. The features of soundproof hood design. IInd all-Russian conference with international participation "Protection of Population from Increased Noise Impact" March 17-19, 2009 St. Petersburg, pp. 529-535.

8. M. Fessina, R. Starobinsky Decreasing of car intake noise, radiated though the engine compartment. Proceedings. Euro-Noise-95, Lyon (France), 21-23 March, 1995, vol. 3, p. 735740.

9. S.M. Vakhitova, I.F. Shaehova, E.I. Zharin Study of vibro-acoustic properties of composite materials based on polyurethane injection- IOP Conference Series: Materials Science and Engineering International Scientific Conference on Innovation Mechanical Engineering Technologies, Equipment and Materials 2015, IMTOM 2015 Kazanskaya Yarmarka Kazan: Russian Federation; 2 Desember through 4 Desember

10. M. Johansmann and J.Saner, A new tool for three - dimensional non-contact vibration measurement in automotive applications, SAE Paper No. 2005-26-052, 2005.

11. M. Johansmann and J.Saner, A new tool for three - dimensional non-contact vibration measurement in automotive applications, SAE Paper No. 2005-26-052, 2005.

12. Heckl M., Müller H.A. Reference book on technical acoustics. Trans. from German by B.D. Vinogradov and N.M. Kolyartsev. Leningrad, Shipbuilding, 1980, - 439 p.

13. M.I. Fessina., R.N.Starobinsky Decreasing external noise of small car, Pr. of INTERNOISE-93, Leuven, Belgium, August, 24-26, 1993, p.

14. M. Fritzche, J.Schell, S.Frank and M.Johansmann, A new method for measurement of rotating objects utilizing lazer Doppler vibrometry combined with an optical derotator/ Proceedings of the 17th International Congress on Sound and Vibration (ICSV 17), Cairo, Egypt, 18th July 2010. 
15. S.M. Vakhitova, I.F. Gumerov, L.N. Shafigullin, I.F. Shaehova, Noise absorbing composite materials applied in domestic trucks" - IOP Conference Series: Materials Science and Engineering International Scientific Conference on Innovation Mechanical Engineering Technologies, Equipment and Materials 2013, IMETEM 2013; Kazanskaya Yarmarka Kazan: Russian Federation; 25 September 2014 through 27 September 2014. IOP Conference Series: Materials Science and Engineering, Volume 69, Issue 1, 2014, Article number 012011, DOI: $10.1088 / 1757-899 \mathrm{X} / 69 / 1 / 012011$

16. Vakhitova S.M., Ganiev M.M., Zharin E.I. Evaluation of noise characteristics of truck engine operation. Innovations of technical solutions in engineering and transport: the collection of articles from All-Russian Scientific and Technical Conference for Young Scientists and Students with International Participation / MNITS PGSHA. - Penza: RIO PGSHA, 2015. pp. 81-83.

17. Shafigullin L.N., Shayakhmetova G.R., Shafigullina A.N., Vakhitova S.M. The study of physical and mechanical properties of glass-filled polyurethane materials manufactured by the use of "Fiber Composite Spraying" technology. New technologies, materials and equipment of Russian aerospace industry: All-Russian scientific-practical conference with international participation, August 10 - 12, 2016: Collection of reports. Volume 1. Kazan: Publishing House of the Academy of Sciences of the Republic of Tatarstan, 2016. V. 1. pp. 897 - 900.

18. Vakhitova S.M., Shaekhova I.F., Ganiev M.M. Investigation of vibration-absorbing and sound-absorbing properties of matrix and filled composite materials on the basis of a modified polyurethane matrix [electronic collection of the conference proceedings] / Moscow State University. Technical University named after N.E. Bauman, the Union of Machine Builders of Russia. - Moscow: MSTU, 2015. - 1154 p .: ill. 952-956 pp.

19. Gumerov I.F., Shafigullin L.N., Vakhitova S.M. Thermal conductivity of vibroacoustic filled polyurethane composite materials. "Bulletin of the Kazan State Technical University named after A.N. Tupolev. Publishing house of the Kazan State Technical University (KNITU-KAI), 2016. V.4. pp. 58-61.

20. Shayhova I.F., Zharin E.I., Vakhitova S.M. The study of thermal conductivity of acoustic polyurethane composite materials. Bulletin of Kazan Technological University. - Kazan. 2016. № 23. pp. 45-46

21. Enin P.V. Noise reduction from vibration-excited thin-walled metal structures using piece vibration-damping inserts: the thesis from the Candidate of Tech. sciences: 01.04.06 Voronezh, 2006. 
How to cite this article:

Shaehova I F, Vakhitova S M, Gumero I F. Development of a multilayer structure for power unit acoustic shielding. J. Fundam. Appl. Sci., 2017, 9(2S), 1008-1017. 